\title{
CONCEPÇÃO PEDAGóGICA DA DCN E DA BNCC: ALGUMAS REFLEXÕES (IM)PERTINENTES
}

\author{
PEDAGOGICAL CONCEPTION OF DCN AND BNCC: \\ SOME (IN)PERTINENT REFLECTIONS
}

\author{
Joselice da Rocha Leal | Lattes | joselice.leal@gmail.com \\ Universidade Federal de Santa Catarina
}

Aline Moraes Lima | Lattes | alinemoraes.tj@gmail.com Universidade Federal de Santa Catarina

\begin{abstract}
Resumo: Este artigo é resultado das constantes inquietações despertadas a partir da ascensão da Base Nacional Comum Curricular (BRASIL, 2017), que está sendo objeto de discussão e formação em todas as redes de ensino e em escolas públicas e privadas de todo o país. Diante disso, o objetivo deste trabalho é entender as demandas nacionais que resultaram no surgimento do documento, bem como sua concepção pedagógica comparada aos documentos anteriores, como as Diretrizes Curriculares Nacionais da Educação Básica (BRASIL, 2013) e as demandas apontadas pelo Plano Nacional de Educação (BRASIL, 2014). Para tal, buscou-se compreender o conceito de competência presente na BNCC e trazer apontamentos de autores e outros documentos que também exploram o termo, juntamente com outras questões, como a fragmentação dos conteúdos e a avaliação em larga escala - possíveis discussões a partir da leitura do documento. Nesse sentido, foi possível perceber a forte relação que há entre a educação e o mercado de trabalho e o papel que a escola vem sendo forçada a desempenhar no cenário social brasileiro, o que reforça a necessidade de novas reflexões sobre o assunto em questão.
\end{abstract}

Palavras-chave: Base Nacional Comum Curricular. Diretrizes Curriculares Nacionais da Educação Básica. Competências. Currículo. Avaliação.

Abstract: This article is a result of the constant concerns arisen by Base Nacional Comum Curricular (BNCC) (BRASIL, 2017), which is being discussed and studied in continuous training for teaching professionals of all public and private schools across the country. Thus, the objective of this paper is to understand the national demands that resulted in the 
emergence of the document, as well as its pedagogical conception compared to previous documents, such as the Diretrizes Curriculares Nacionais da Educação Básica (DCN) (BRASIL, 2013) and the demands pointed out by the Plano Nacional de Educação (BRASIL, 2014). Therefore, we sought to understand the concept of competence present at $\mathrm{BNCC}$ and to bring reflections from authors and excerpts from other documents that also explore the term, as well as other issues, such as content fragmentation and largescale evaluation, possible discussions raised by the reading of the document. In this sense, it was possible to perceive the strong relationship that exists between education and the labor market and the role that the school has been forced to play in the Brazilian social scenario, which reinforces the need for new reflections on the subject in question.

Keywords: Base Nacional Comum Curricular. Diretrizes Curriculares Nacionais da Educação Básica. Competences. Curriculum. Evaluation.

\section{INTRODUÇÃO}

A justificativa para a criação de uma Base Nacional Comum Curricular (BNCC) é apresentada a partir da Constituição Nacional de $1988^{1}$ e da Lei de Diretrizes e Bases da Educação Nacional (LDB) de $1996^{2}$. A BNCC foi criada para ser, como o próprio documento apregoa, uma "referência nacional para a formulação dos currículos dos sistemas e das redes escolares dos Estados, do Distrito Federal e dos Municípios e das propostas pedagógicas das instituições escolares” (BRASIL, 2017, p. 8).

As discussões em torno da construção de bases gerais para a elaboração dos currículos da escola básica ocorreram em diferentes momentos da história da educação nacional e se tornaram mais recorrentes na década de 1990, sendo objeto de grande interesse dos órgãos diretores da educação, que as conduziam, dentre outras razões, devido à necessidade de mudanças que visavam a democratização e a modernização do ensino (GONTIJO, 2015).

Sobre os documentos oficiais que antecederam à BNCC e anteriores à aprovação das novas Diretrizes Curriculares Nacionais Gerais para a Educação Básica (DCNs) em 2013, Gontijo (2015, p. 178) aponta que eles:

\footnotetext{
1 Art. 210. Serão fixados conteúdos mínimos para o ensino fundamental, de maneira a assegurar formação básica comum e respeito aos valores culturais e artísticos, nacionais e regionais. (BRASIL, 1988, Art. 210, grifo nosso).

2 Art. 26. Os currículos da educação infantil, do ensino fundamental e do ensino médio devem ter base nacional comum, a ser complementada, em cada sistema de ensino e em cada estabelecimento escolar, por uma parte diversificada, exigida pelas características regionais e locais da sociedade, da cultura, da economia e dos educandos. (BRASIL, 1996, Art. 26, grifo nosso).
} 
Não pretenderam ser o currículo da escola, mas apenas fornecer, num primeiro momento, subsídios para organização dos currículos escolares e, num segundo momento, mais recentemente, metas para a construção da qualidade da educação básica, no contexto de implementação dos sistemas de avaliação em larga escala, que, por sua vez, buscam a melhoria da qualidade da educação por meio da medição de resultados.

Com a atualização das DCNs, permaneceu a proposição de vincular questões curriculares à avaliação, visto que "são estas diretrizes que estabelecem a base nacional comum, responsável por orientar a organização, articulação, o desenvolvimento e a avaliação das propostas pedagógicas de todas as redes de ensino brasileiras" (MERCADANTE, 2013, p. 4). Este documento, apesar de manter o mesmo modelo de implantação vertical ${ }^{3}$, ainda mantém um caráter mais aberto e menos restritivo ao objetivar:

I- Sistematizar os princípios e diretrizes gerais da Educação Básica contidos na Constituição, na LDB e demais dispositivos legais, traduzindo-os em orientações que contribuam para assegurar a formação básica comum nacional, tendo como foco os sujeitos que dão vida ao currículo e à escola; II - Estimular a reflexão crítica e propositiva que deve subsidiar a formulação, execução e avaliação do projeto político-pedagógico da escola de Educação Básica;

III - Orientar os cursos de formação inicial e continuada de profissionais - docentes, técnicos, funcionários - da Educação Básica, os sistemas educativos dos diferentes entes federados e as escolas que os integram, indistintamente da rede a que pertençam. (BRASIL, 2013, p. 7-8).

É nesse contexto de implantação vertical e de referência para os sistemas de avaliação que, de acordo com Geraldi (2015, p. 384), “[... ] surge a Base Nacional Comum Curricular (BNCC), também ela produto de consultorias universitárias, de comitês de especialistas, de técnicos competentes”. Esse documento norteador de currículo se diferencia das DCNs, principalmente por apresentar um maior "engessamento", sugerindo maior uniformização do ensino e um caráter mais descritivo de saberes e conteúdos a serem ensinados e apreendidos.

\footnotetext{
${ }^{3}$ Geraldi (2015, p. 383) apresenta um panorama da década de 1990, logo depois do período de redemocratização. Ele explica que, após um curto período de participação popular efetiva na condução da elaboração de propostas curriculares, as escolas foram inundadas por documentos oficiais, "definindo metas, objetivos, modos de gestão, índices desejados" e concentrando o processo de formulação de propostas curriculares mais na atuação de técnicos, consultores e assessores especializados. Sob a justificativa de efetuar as mudanças com rapidez, inicia-se "a implantação verticalizada do novo como exigência e não como opção abraçada pelos verdadeiros agentes educativos”.
} 
Apesar de, na apresentação desse documento normativo, o então Ministro da Educação Rossieli Soares da Silva declarar que a BNCC foi "concluída após amplos debates com a sociedade e os educadores do Brasil” (SILVA, 2017, p. 5), constata-se que o processo controverso de construção da BNCC se deu de maneira a prestigiar o setor privado como a voz mais ouvida nesse processo (TRICHES; ARANDA, 2016). Além disso, muitas críticas foram tecidas durante a construção desse documento, especialmente no que tange ao questionamento sobre a real necessidade de um novo documento norteador de currículo; à imposição da visão mercadológica e da avaliação padronizada; e ao mecanismo de homogeneização/padronização que reproduz a exclusão social e escolar (TRICHES; ARANDA, 2016).

É importante ressaltar aqui que essa visão mercadológica ligada à educação é algo que está sendo discutido há muitos anos. Freitas (2012), em seu artigo intitulado Os Reformadores empresariais da educação: da desmoralização do magistério à destruição do sistema público de educação, destaca que a lógica de pensar a educação a partir das modificações realizadas no campo de produção já vinha sendo destacada desde os anos de 1980, a qual Saviani (1986) chamou de "pedagogia tecnicista" ${ }^{4}$ que, hoje, é utilizada sob a ótica das expectativas de aprendizagens e medição de resultados a partir de testes padronizados.

O propósito deste artigo é direcionado, então, da seguinte maneira: identificar a concepção pedagógica da BNCC, considerando o antagonismo existente entre abordagens teóricas que enfatizam o conhecimento em si ou o conhecimento para fazer algo (MACEDO, 2016) e tomando as DCN's (BRASIL, 2013) como contraponto. Para tanto, optamos pela análise das concepções presentes no Plano Nacional da Educação (PNE 2014-2024) (BRASIL, 2014) e na BNCC. Buscamos respaldar nossa análise em Gontijo (2015), que relacionará o documento da BNCC com as avaliações em larga escala, juntamente com Luckesi (2011) e Geraldi (2015), que também tratarão do tema da avaliação com enfoques diferentes. Para tratar do conceito de competência presente na BNCC, além dos textos dos documentos oficiais, buscamos Perrenoud (1999) que possui ideias compatíveis às encontradas no documento da base.

\section{DO PONTO DE VISTA PEDAGÓGICO, DE ONDE A BNCC SURGE?}

A necessidade de uma base comum curricular em nível nacional vem sendo apontada há anos e trazida a cada novo documento, reforçando sua necessidade; até que, em

\footnotetext{
${ }^{4}$ Para Saviani (1986, p. 15-16), “[...] na pedagogia tecnicista [...] é o processo que define o que professores e alunos devem fazer, e assim também quando e como o farão.”
} 
2015, obtivemos uma versão preliminar da base, tendo sua versão final homologada dois anos depois. $\mathrm{O}$ texto introdutório do próprio documento a define:

\begin{abstract}
A Base Nacional Comum Curricular (BNCC) é um documento de caráter normativo que define o conjunto orgânico e progressivo de aprendizagens essenciais que todos os alunos devem desenvolver ao longo das etapas e modalidades da Educação Básica, de modo a que tenham assegurados seus direitos de aprendizagem e desenvolvimento, em conformidade com o que preceitua o Plano Nacional de Educação (PNE). (BRASIL, 2017, p. 7, grifo original do documento).
\end{abstract}

Embora a BNCC não deixe claro qual seja seu referencial teórico, é possível, por meio da leitura de seu texto, encontrar sinais que nos indiquem em que concepção pedagógica o documento está alicerçado - a Pedagogia das Competências. Um dos conceitos presentes na BNCC e que embasa sua constituição é o de competências. De acordo com o próprio documento:

Na BNCC, competência é definida como a mobilização de conhecimentos (conceitos e procedimentos), habilidades (práticas, cognitivas e socioemocionais), atitudes e valores para resolver demandas complexas da vida cotidiana, do pleno exercício da cidadania e do mundo do trabalho. (BRASIL, 2017, p. 8, grifo original do documento).

É possível perceber que essa definição de competência explicitada na BNCC utiliza-se do texto do artigo $32^{5}$ da LDB, para listar o que se é mobilizado; e do artigo $205^{6}$ da Constituição de 1988, para apresentar o objetivo final da mobilização dos conhecimentos, habilidades, atitudes e valores, que é lidar com as questões, ditas complexas, da vida cotidiana, do exercício da cidadania e do mundo do trabalho. No entanto, ao fazer esse paralelismo, percebe-se que há uma disparidade quanto ao primeiro item, uma vez que, enquanto a Constituição apresenta como um dos objetivos da educação o "pleno desenvolvimento da pessoa", a competência, de acordo com a BNCC, teria como alvo as "demandas complexas da vida cotidiana".

Essa distinção pode sugerir que a ideia de competência apresentada pela BNCC está ligada mais à preparação dos indivíduos para fazer do que à formação e ao pleno desenvolvimento deles. Embora a BNCC pareça sugerir em suas competências gerais uma

\footnotetext{
5 "[...] o desenvolvimento da capacidade de aprendizagem, tendo em vista a aquisição de conhecimentos e habilidades e a formação de atitudes e valores"(BRASIL, 1996, Art. 32, \ $3^{\circ}$, grifo nosso)

6 "A educação, direito de todos e dever do Estado e da família, será promovida e incentivada com a colaboração da sociedade, visando ao pleno desenvolvimento da pessoa, seu preparo para o exercício da cidadania e sua qualificação para o trabalho." (BRASIL, 1988, Art. 205, grifo nosso).
} 
formação integral dos educandos, a própria definição de competência destoa desses pressupostos, uma vez que aponta, como objetivo, a preparação dos indivíduos para operar em sua vida cotidiana, no exercício da cidadania e do trabalho.

Essa mesma ideia de ênfase no fazer se faz presente na análise que Gontijo (2015, p. 187) faz acerca da alfabetização na BNCC:

[...] o caráter político da alfabetização continua ausente do texto preliminar da BNCC. A preocupação é com a instrumentalização técnica dos sujeitos para responderem a demandas sociais e profissionais colocadas pela sociedade moderna.

É evidente que reconhecemos que o artigo 205 da Carta Magna se refere aos objetivos da educação como um todo e que a presente discussão se refere à definição de competência. Apesar disso, cabe-se perguntar: se para conceituar competência recorreu-se às leis brasileiras, no que tange à educação, realizando uma colagem de termos, por que abandonar a expressão "pleno desenvolvimento da pessoa" e acrescentar em seu lugar "demandas complexas da vida cotidiana"?

Ao iniciar a discussão sobre seus fundamentos pedagógicos, a BNCC aponta o conceito de competência como sendo algo que pode ser inferido nos artigos 32 e 35 da LDB. Ao recorrer ao texto indicado, deparamo-nos com as seguintes definições:

Art. 32. O ensino fundamental obrigatório, com duração de 9 (nove) anos, gratuito na escola pública, iniciando-se aos 6 (seis) anos de idade, terá por objetivo a formação básica do cidadão, mediante:

I - o desenvolvimento da capacidade de aprender, tendo como meios básicos o pleno domínio da leitura, da escrita e do cálculo;

II - a compreensão do ambiente natural e social, do sistema político, da tecnologia, das artes e dos valores em que se fundamenta a sociedade;

III - o desenvolvimento da capacidade de aprendizagem, tendo em vista a aquisição de conhecimentos e habilidades e a formação de atitudes e valores;

IV - o fortalecimento dos vínculos de família, dos laços de solidariedade humana e de tolerância recíproca em que se assenta a vida social. (BRASIL, 1996, Art. 32).

Art. 35. O ensino médio, etapa final da educação básica, com duração mínima de três anos, terá como finalidades:

I - a consolidação e o aprofundamento dos conhecimentos adquiridos no ensino fundamental, possibilitando o prosseguimento de estudos;

II - a preparação básica para o trabalho e a cidadania do educando, para continuar aprendendo, de modo a ser capaz de se adaptar com flexibilidade a novas condições de ocupação ou aperfeiçoamento posteriores; 
III - o aprimoramento do educando como pessoa humana, incluindo a formação ética e o desenvolvimento da autonomia intelectual e do pensamento crítico;

IV - a compreensão dos fundamentos científico-tecnológicos dos processos produtivos, relacionando a teoria com a prática, no ensino de cada disciplina. (BRASIL, 1996, Art. 35).

O primeiro excerto trata das formas pelas quais se poderá garantir a formação básica do cidadão no ensino fundamental, enquanto o segundo apresenta as finalidades do ensino médio. No artigo 32, não existe menção ao termo competência, mas percebe-se, como dito anteriormente, que a construção da definição do termo na BNCC foi realizada por meio da junção do texto do inciso III desse artigo com parte do artigo 205 da Constituição Federal. A noção de preparação para o trabalho e a cidadania também está expressa no inciso II do artigo 35 da LDB, como visto acima.

Nessa discussão sobre o conceito de competências na BNCC, é importante notar que, em 2017, foi incluído na LDB o artigo 35-A, por meio da Lei no 13.415. Dentre outras alterações e acréscimos, o artigo inclui especificações sobre a BNCC. Interessante notar que o termo competências, entendido conforme a definição da BNCC, aparece em três das quatro ocorrências relevantes que discutiremos mais à frente. Assim, constata-se que ocorreu um processo político recente no intuito de incluir na LDB o termo competências e, a partir disso, justificar e legitimar o seu uso na BNCC.

Antes da promulgação dessa lei, o termo competências já aparecia na LDB, mas com outros significados. Atualmente, o termo, juntamente com sua variação no singular, aparece 10 vezes na lei, sendo que, na maioria das vezes, se refere à "esfera ou área de responsabilidade" do ente federativo (Art. 40-A; Art. 5, $\ 1$; Art. 10, parágrafo único; Art. 11, inciso $V$ ). Em outro artigo, o termo pode ser entendido como um dos critérios para organização das séries na educação básica (Art. 23) e, em outro momento, como aquilo que compete ao trabalho do profissional da educação (Art. 61, parágrafo único, inciso I). Apesar dessas situações em que o termo possui um significado mais genérico, alguns usos do termo competências nos chamam a atenção por se aproximarem do conceito de competências da BNCC:

Estabelecer, em colaboração com os Estados, o Distrito Federal e os Municípios, competências e diretrizes para a educação infantil, o ensino fundamental e o ensino médio, que nortearão os currículos e seus conteúdos mínimos, de modo a assegurar formação básica comum; (BRASIL, 1996, Art. 9, inciso IV, grifo nosso).

A organização das áreas de que trata o caput e das respectivas competências 
e habilidades será feita de acordo com critérios estabelecidos em cada sistema de ensino. (BRASIL, 1996, Art. 36, \$1ㅜㅡ, grifo nosso) (Redação dada pela Lei no 13.415 , de 2017).

Para efeito de cumprimento das exigências curriculares do ensino médio, os sistemas de ensino poderão reconhecer competências e firmar convênios com instituições de educação a distância com notório reconhecimento, mediante as seguintes formas de comprovação: (BRASIL, 1996, Art. 36, \$ 11, grifo nosso) (Incluído pela Lei no 13.415 , de 2017).

O processo seletivo referido no inciso II considerará as competências e as habilidades definidas na Base Nacional Comum Curricular. (BRASIL, 1996, Art. 44, $₫ 3^{\circ}$, grifo nosso) (Incluído pela lei no 13.415 , de 2017).

Dentre esses excertos, o único que já constava na LDB antes de 2017 é o artigo 9o, inciso IV. Apesar de parecer que há uma relação entre competências e formulação de diretrizes para nortear os currículos e seus conteúdos mínimos, o significado do termo competências nesse trecho parece estar relacionado àquilo que é próprio de cada etapa, ou seja, quais as responsabilidades da educação infantil, do ensino fundamental e do ensino médio.

Ao que parece, há uma tentativa de apresentar a BNCC como um documento neutro, isento de posições ideológicas, por conseguinte, sem base teórica explicitada. Com esse intuito, houve um movimento no sentido de conceituar competências a partir da legislação. No entanto, deve-se notar que os termos competências e habilidades, no sentido proposto pela BNCC, são incluídos no texto da LDB no ano de 2017, período em que a BNCC estava prestes a ser homologada e envolvida em vários embates políticos - momento em que um governo mais de esquerda havia sido substituído por outro com tendências liberais bastante nítidas. Nesse sentido, vale destacar a impossibilidade de se construir um currículo neutro, pois "as normatizações curriculares perpassam por relações de poder" (TRICHES; ARANDA, 2016, p.82).

Em consonância com esse pensamento, Freitas, Silva e Leite (2018) reportam-se às ideias de Michael W. Apple expressas no texto A política do conhecimento oficial: faz sentido a ideia de um currículo nacional?, para explicar que o currículo ultrapassa a ideia de um conjunto neutro de saberes. De acordo com os autores,

[...] o currículo é campo político que envolve tensões, negociações e acordos culturais e econômicos, o que acaba por legitimar determinados saberes e dar respaldo a certos grupos. Aqueles que ganham visibilidade acabam por produzir um discurso de dominação que ofusca os outros saberes e os atribui um caráter ilegítimo ou de menor valia. (FREITAS; SILVA; LEITE, 2018, p. 859). 
Dessa forma, é importante destacar que, apesar de o conceito de competência ser construído na BNCC a partir da legislação brasileira, o seu uso na versão final desse documento demonstra estar alinhado com a tendência internacional das últimas décadas - desenvolver abordagens de aprendizagem baseada no trabalho remunerado, preparando os indivíduos para atender às demandas do mercado. Ao compreender o contexto político e sócio-histórico que o Brasil tem vivido recentemente, percebe-se que essa política curricular brasileira

favorece uma visão neoliberal, neoconservadora e centralizadora, construindo a educação pública como espaço cada vez mais aberto para a atuação da iniciativa privada e, por outro lado, promovendo a dissolução de articulações em defesa da formação humana crítica. (SOUZA; GIORGI; ALMEIDA, 2018, p. 104).

\section{PEDAGOGIAS DAS COMPETÊNCIAS E PEDAGOGIAS ATIVAS NA BNCC}

A BNCC, no mesmo parágrafo em que diz que o conceito de competência "pode ser inferido no texto da LDB", também apresenta que o termo adotado no documento "marca a discussão pedagógica e social das últimas décadas" (BRASIL, 2017, p.13).

De fato, desde a década de 1980, o termo é debatido pela comunidade acadêmica e foi incorporado às agendas das instituições de todo o mundo, a partir dos anos 1990 (BORGES, 2010). Cabe ressaltar que discussões pedagógicas contra-hegemônicas e suscitadas como alternativa à pedagogia dominante também acontecem no cenário nacional desde a década de 1970, a partir das chamadas pedagogias críticas, a exemplo da pedagogia histórico-crítica ${ }^{7}$, que se preocupa com a forma como o aluno irá se apropriar do conhecimento historicamente produzido.

A BNCC assume que adota o mesmo enfoque que, segundo o documento, estados e municípios brasileiros e diferentes países têm assumido no movimento de tomar o desenvolvimento de competências como fator norteador na construção de currículos. Além disso, o documento destaca que esse também é o enfoque das avaliações internacionais da Organização para a Cooperação e Desenvolvimento Econômico (OCDE) e da Organização das Nações Unidas para a Educação, a Ciência e a Cultura (Unesco) (BRASIL, 2017, p. 16).

Baseada nas ideias de Marise Ramos no livro Pedagogia das competências: autonomia ou adaptação?, Macedo (2016, p. 56) aponta que muitas reformas curriculares já foram

\footnotetext{
${ }^{7}$ No Brasil, a pedagogia histórico-crítica surge nos anos de 1980, sendo que seu principal representante foi o professor Dermeval Saviani. Essa teoria desenvolveu-se aos poucos e assumiu alguns pressupostos teóricos vindos de outras áreas, como o materialismo histórico marxista, a epistemologia dialética; na psicologia, os trabalhos da Escola de Vigotski e, na área da educação, as influências de George Snyders e Antonio Gramsci, Mario Alighiero Manacorda e Bogdan Suchodolski (SAVIANI, 2008).
} 
empreendidas em vários países do mundo a partir da concepção pragmática do conhecimento, em que se prioriza o "gerencialismo neoliberal do 'aprender a aprender' progressivista, bem como as propostas de ensino por competências defendidas tanto por Morin (2011) e Perrenoud (1999) quanto por autores vinculados à educação para o trabalho”.

Sem dúvida, o termo competência é polissêmico e, mesmo no âmbito da literatura pedagógica, assume flutuantes significados. No entanto, encontramos em Phillippe Perrenoud, um dos autores mais relevantes na defesa da pedagogia das competências, ideias muito próximas ao que é defendido na BNCC. Ao se referir a Perrenoud e a outros teóricos alinhados à mesma perspectiva, Borges (2010, p. 40) observa que “[... ] seus trabalhos fundamentaram pesquisas desenvolvidas no âmbito de organismos internacionais, inspirando grande parte de documentos produzidos multilateralmente sobre esse tema e que, posteriormente, traduziram-se em preceitos de política nacionais na área educacional".

Em suas obras, Perrenoud questiona o fato de as escolas limitarem-se à transmissão do conhecimento, se podem ampliar para o desenvolvimento das competências. De acordo com o autor:

\footnotetext{
São múltiplos os significados da noção de competência. Eu a definirei aqui como sendo uma capacidade de agir eficazmente em um determinado tipo de situação, apoiada em conhecimentos, mas sem limitar-se a eles. Para enfrentar uma situação da melhor maneira possível, deve-se, via de regra, pôr em ação e em sinergia vários recursos cognitivos complementares, entre os quais estão os conhecimentos. (PERRENOUD, 1999, p.7).
}

Aqui, o conhecimento é sugerido pelo autor como um dos meios para se desenvolver a competência; dessa forma, a competência é a protagonista no processo educativo, não mais o conhecimento. É possível, a partir de uma leitura da obra de Perrenoud, concluir que o autor propõe uma crítica ao modelo tradicional de educação e defende que seu avanço se dará por meio do ensino de competências.

Observando o texto da BNCC, percebe-se que as competências, assim como defendido por Perrenoud (1999), assumem a proeminência sobre os conteúdos, sendo que estes devem estar a serviço do desenvolvimento daquelas nos currículos da educação infantil, do ensino fundamental e do ensino médio. A seção do documento Os fundamentos pedagógicos da BNCC, indica que:

Segundo a LDB (Artigos 32 e 35), na educação formal, os resultados das aprendizagens precisam se expressar e se apresentar como sendo a 
possibilidade de utilizar o conhecimento em situações que requerem aplicá-lo para tomar decisões pertinentes. A esse conhecimento mobilizado, operado e aplicado em situação se dá o nome de competência. (BRASIL, 2017, p. 15, grifos do documento).

Ao discutir em seu artigo sobre a falsa oposição entre conhecimento para fazer algo e conhecimento em si durante o processo de construção da BNCC, Macedo (2016) argumenta que essa disputa naturaliza o sentido de currículo como controle, especialmente num mundo multicultural em que a intensificação das estratégias de controle torna a qualidade dependente desse controle. A autora explica que:

A tradição de objetivos associados a conteúdos - o que, com alguma licença, talvez se pudesse chamar de eficiência social - é contraposta a competências genéricas (ou capacidades gerais) aptas a dar conta dos novos modos de organização e legitimação do conhecimento e, principalmente, passíveis de ser dominados por todos. Tanto a teoria crítica como o progressivismo já vinham, historicamente, denunciando o caráter abstrato do conhecimento disciplinar. $\mathrm{O}$ discurso da competência não é, certamente, o primeiro a apontar para o saber contextual e, seguramente, o faz de maneira distinta daquela propagada tanto por uma quanto por outro. (MACEDO, 2016, p. 57).

De acordo com Macedo (2016), na época de construção da BNCC (2015 e 2016), o conhecimento pragmático e o conhecimento em si eram antagonistas no discurso acadêmico. No entanto, eles se tornavam equivalentes no preenchimento dos sentidos de base curricular comum nacional no Brasil, ao favorecer o controle (nacional) do currículo. Hoje, após a homologação da BNCC, percebemos que o sentido de competência como conhecimento para fazer algo prevaleceu. No entanto, mesmo que não o fosse, a busca pela qualidade da educação continuaria ligada às avaliações e às formas que permitem medir em números as melhorias educacionais.

Ainda no que se refere à presença da Pedagogia das Competências na BNCC, é preciso destacar que a noção de competência de Perrenoud está vinculada ao pensamento piagetiano (MACEDO, 2016, p. 57-58). Dentre outras implicações desse vínculo, entende-se que a ênfase do processo educativo se encontra no aprendiz. Ao falar acerca da mudança que deve ocorrer na relação dos professores com o saber, sua identidade e suas competências profissionais, Perrenoud (1999, p. 57) afirma que

[...] estamos a caminho de um ofício novo, cuja meta é antes fazer aprender do que ensinar. A abordagem por competências junta-se às exigências da focalização sobre o aluno, e dos métodos ativos [...] 
Em harmonia com esse pensamento, a BNCC retoma o PNE e apresenta claramente, como estratégia de melhoria na educação básica, a ênfase na aprendizagem:

Nesse sentido, consoante aos marcos legais anteriores, o PNE afirma a importância de uma base nacional comum curricular para o Brasil, com o foco na aprendizagem como estratégia para fomentar a qualidade da Educação Básica em todas as etapas e modalidades (meta 7), referindose a direitos e objetivos de aprendizagem e Desenvolvimento. (BRASIL, 2017, p. 12).

Além disso, nota-se, na BNCC, um discurso de ensinar a partir das necessidades e interesses dos alunos, como é possível observar no seguinte trecho:

Independentemente da duração da jornada escolar, o conceito de educação integral com o qual a BNCC está comprometida se refere à construção intencional de processos educativos que promovam aprendizagens sintonizadas com as necessidades, as possibilidades e os interesses dos estudantes e, também, com os desafios da sociedade contemporânea. Isso supõe considerar as diferentes infâncias e juventudes, as diversas culturas juvenis e seu potencial de criar novas formas de existir. (BRASIL, 2017, p. 14).

Nesse sentido, quando compreendemos que o ensino deve partir do interesse do aluno, preocupamo-nos com o aluno empírico, que, segundo Saviani (2013), é aquele que sente interesse pelo conteúdo imediato, momentâneo. $\mathrm{O}$ autor o diferencia do aluno concreto, que é aquele que recebe os conteúdos selecionados pelo professor que atenderão às suas necessidades de aprendizagem, que transcende o conhecimento pragmático e cotidiano. $\mathrm{O}$ autor destaca que "o professor [...] é posto na condição de viabilizar essa apreensão por parte dos alunos, realizando a mediação entre o aluno e o conhecimento que se desenvolveu socialmente" (SAVIANI, 2013, p. 122). Evidencia-se, aqui, que é o professor quem precisa possuir as ferramentas para a seleção de conteúdos, pois o aluno ainda não as tem; o que o aluno possui são interesses que partirão de suas necessidades mais imediatas, não, como sugere o autor, necessidades concretas que levem em conta a apreensão das relações sociais de forma sintética.

O ensino, a partir da perspectiva de Perrenoud (1999), considera sempre a aquisição de um conhecimento com vistas ao contexto. Dessa maneira, o aprendizado deve ser associado a uma ou mais práticas sociais, com sentido para os alunos, com o intuito de que eles assimilem competências para lidar com situações da vida. $\mathrm{O}$ autor explica que: 
Enquanto os exercícios escolares não têm consequências para outrem, uma abordagem por competências ataca problemas reais, da "vida de verdade”, e frequentemente diz respeito a pessoas que não pertencem à turma, como destinatários do projeto ou pessoas-recursos cuja cooperação é fundamental. (PERRENOUD, 1999, p.78).

Mais uma vez, em consonância com Perrenoud (1999), a BNCC também aponta a necessidade de se ensinar o conhecimento de maneira pragmática, com vistas à aplicação na vida, além de ressaltar novamente o protagonismo do aluno:

Assim, a BNCC propõe a superação da fragmentação radicalmente disciplinar do conhecimento, o estímulo à sua aplicação na vida real, a importância do contexto para dar sentido ao que se aprende e o protagonismo do estudante em sua aprendizagem e na construção de seu projeto de vida. (BRASIL, 2017, p. 15).

No que se refere à atuação do professor, Perrenoud (1999) coloca-o como parceiro dos alunos no processo de aprendizagem. A tarefa dos professores "lida com a regulação do processo e, frequentemente, com a construção de problemas de complexidade crescente" (PERRENOUD, 1999, p.59). Para o autor, é importante que o professor identifique e ajude o aluno a identificar o obstáculo e fazer dele o principal ponto da ação pedagógica. Ao comentar sobre certos colégios experimentais, o autor destaca o trabalho dessas instituições com projetos em que:

[...] os professores tornam-se estimuladores e pessoas-recursos. Desse modo, os conhecimentos disciplinares são introduzidos graças a um processo de projeto, isto é, de maneira incompleta, não-planejada, não-sistemática, em suma, "pouco séria", não vacilarão em dizer os partidários de um texto do conhecimento percorrido na boa direção. Em contrapartida, os conhecimentos serão mobilizados em situações nas quais sua pertinência é evidente, tornando-se verdadeiras ferramentas, e não somente matérias de exames, e tendo um sentido. (PERRENOUND, 1999, p. 86, grifo nosso).

Ao tratar sobre os professores, a BNCC indica que "a primeira tarefa de responsabilidade direta da União será a revisão da formação inicial e continuada dos professores para alinhá-las à BNCC” (BRASIL, 2017, p. 21). Dessa forma, é nítida a intenção de formar professores a partir da Pedagogia das Competências. Deve-se esclarecer que o próprio Perrenoud (1999, p. 57, grifo nosso) diz que “[...] o sistema educacional só pode formar em competências desde a escola se a maioria dos professores aderir livre- 
mente a essa concepção de sua tarefa”. No entanto, essa liberdade é tolhida uma vez que, na prática, o documento da BNCC se impõe às redes de ensino com prazo marcado de adequação curricular e metodológica. Dessa forma, tal fixação está em desacordo com o próprio Perrenoud (1999), que em sua proposição anterior destacou que o professor deveria aderir à proposta livremente.

Observando as habilidades descritas na BNCC em todos os anos do ensino fundamental, é possível ver que o professor é colocado como mediador. Com muita frequência, nos deparamos com expressões do tipo "com a ajuda do professor", "com a mediação do professor", “com o apoio do professor”. Dessa forma, vemos que a ideia do papel do professor expressa na BNCC se aproxima muito da visão das pedagogias ativas, dentre elas a Pedagogia das Competências. E, como consequência disso, distingue-se de concepções em que ao professor é tributada a ação propositiva, em que o docente é o mais experiente, o que ensina, conforme discute Saviani (2013), que compreende o professor como aquele que apresenta o conhecimento ao aluno, pois é ele quem "de certo modo, apreendeu as relações sociais de forma sintética”, portanto, é quem viabiliza o conhecimento socialmente produzido ao aluno (SAVIANI, 2013, p. 122).

\section{BNCC: DE ONDE VEM E PARA ONDE VAI...}

A ideia de uma base comum curricular nacional surge com a LDB (BRASIL, 1996, Art. 261), a ser complementada, nos sistemas de ensino e em cada escola, por uma parte diversificada, exigida pelas características regionais e locais da sociedade, da cultura, da economia e dos educandos.

Essa discussão referente à base também surge associada às diretrizes curriculares nacionais: "Estabelecer, em colaboração com os Estados, o Distrito Federal e os Municípios, competências e diretrizes para a educação infantil, o ensino fundamental e o ensino médio, que nortearão os currículos e seus conteúdos mínimos, de modo a assegurar formação básica comum", que surge entre as competências da União no artigo $2^{\circ}$ da LDB (BRASIL, 1996).

Já o PNE, de 2014, que diferencia a BNCC e as DCN’s, nos traz que “União, Estados, Distrito Federal e Municípios definirão [...] a implantação dos direitos e objetivos de aprendizagem e desenvolvimento que configurarão a base nacional comum curricular do ensino fundamental" (BRASIL, 2014, Meta 2). No PNE, a BNCC também aparece rela- 
cionada às metas que falam da universalização do ensino fundamental ${ }^{8}$; à avaliação e ao IDEB $^{9}$; e à formação de professores ${ }^{10}$.

De acordo com a LDB, as Diretrizes definem os conhecimentos da base comum nacional: Língua Portuguesa; Matemática; conhecimento do mundo físico, natural, da realidade social e política, especialmente do Brasil, incluindo-se o estudo da História e das Culturas Afro-Brasileira e Indígena; Arte, em suas diferentes formas de expressão, incluindo-se a música; Educação Física; Ensino Religioso. Sendo que a organização desses componentes, elaborada pelos sistemas educativos, conforme preconizam as Diretrizes, poderiam ser na forma de áreas de conhecimento, disciplinas ou eixos temáticos, preservando-se a especificidade dos diferentes campos do conhecimento, por meio dos quais se desenvolvem as habilidades indispensáveis ao exercício da cidadania, em ritmo compatível com as etapas do desenvolvimento integral do cidadão (BRASIL, 2013, p. 32).

Em 2015, a BNCC é apresentada pelo Ministério da Educação, com o intuito de que a sociedade apresentasse suas sugestões. $\mathrm{O}$ documento não revogava as diretrizes, mas definia áreas de conhecimento para a organização do currículo. Observando a BNCC, podemos perceber que esta atende o previsto no PNE, nas DCN's; e, os princípios que orientam as Diretrizes Curriculares Nacionais se encontram na Constituição Federal de 1988 e no Estatuto da Criança e do Adolescente.

Observando de maneira geral a organização da BNCC, revela-se uma forte preocupação com os objetivos de aprendizagem a serem alcançados e uma organização do currículo em áreas de conhecimento, sendo elas: Ciências da Natureza, Ciências Humanas, Linguagens e Matemática e seus respectivos componentes curriculares.

É importante ressaltar aqui que os componentes curriculares apresentados na BNCC são, na verdade, o que entendemos na organização escolar por disciplinas e que,

\footnotetext{
${ }^{8}$ Meta 2: Universalizar o ensino fundamental de 9 (nove) anos para toda a população de 6 (seis) a 14 (quatorze) anos e garantir que pelo menos $95 \%$ (noventa e cinco por cento) dos alunos concluam essa etapa na idade recomendada, até o último ano de vigência deste PNE. (BRASIL, 2014, Meta 2).

Meta 3: Universalizar, até 2016, o atendimento escolar para toda a população de 15 (quinze) a 17 (dezessete) anos e elevar, até o final do período de vigência deste PNE, a taxa líquida de matrículas no ensino médio para $85 \%$ (oitenta e cinco por cento). (BRASIL, 2014, Meta 3).

9 Meta 7: Fomentar a qualidade da educação básica em todas as etapas e modalidades, com melhoria do fluxo escolar e da aprendizagem de modo a atingir as seguintes médias nacionais para o Ideb (BRASIL, 2014, Meta 7).

${ }^{10}$ Meta 15: Garantir, em regime de colaboração entre a União, os Estados, o Distrito Federal e os Municípios, no prazo de 1 (um) ano de vigência deste PNE, política nacional de formação dos profissionais da educação de que tratam os incisos I, II e III do caput do art. 61 da Lei n 9.394, de 20 de dezembro de 1996, assegurado que todos os professores e as professoras da educação básica possuam formação específica de nível superior, obtida em curso de licenciatura na área de conhecimento em que atuam. (BRASIL, 2014, Meta 15).
} 
apesar de citados dentro de uma grande área do conhecimento, são, posteriormente, separados e organizados em conteúdos por ano escolar, o que nos sugere a fragmentação do ensino e não a articulação das grandes áreas.

Nesse percurso, vamos observando que a BNCC caminha para a normatização curricular ao mesmo tempo em que viabiliza uma melhor organização das avaliações de larga escala e, com elas, possibilita aferir com maior precisão os resultados esperados e os obtidos por estados e municípios brasileiros. É importante observar que o ato de avaliar está presente nas mais diversas atividades cotidianas, avaliamos e somos avaliados constantemente. Na escola, não é diferente. A avaliação surge como forma de, inclusive, organização pedagógica e gestão do ensino e aprendizagem. Luckesi (2011) nos diz que avaliar é um processo mais complexo que medir e está ligado a um posicionamento, a uma tomada de decisões.

Nesse sentido, a avaliação surge como um processo de reorganização constante da prática docente em sala de aula que nos é posta como uma atividade constante, conforme preconiza a LDB, em seu artigo 24:

A verificação do rendimento escolar observará critérios, dentre eles podemos destacar: a) avaliação contínua e cumulativa do desempenho do aluno, com prevalência dos aspectos qualitativos sobre os quantitativos e dos resultados ao longo do período sobre os de eventuais provas finais. (BRASIL, 1996, Art. 24).

Com as mudanças na área da educação, provenientes da globalização e sob influência das políticas públicas neoliberais ${ }^{11}$, na década de 1990, avaliações foram sendo formuladas com o objetivo de ampliar a visão sobre a realidade escolar brasileira, detectando e oferecendo aportes para a sua melhoria.

Os resultados do desempenho obtidos nas avaliações de larga escala serviriam para diagnosticar o desempenho dos estudantes, escolas e professores. É importante entender que, no ambiente político e econômico neoliberal, essas avaliações em larga escala são responsáveis por uma série de encadeamentos no campo educacional, conforme nos apresenta Sousa (2013, p. 66):

[...] oqueseassisteéa proeminência da avaliação emlarga escala, usualmente implementada de modo associado a medidas de descentralização de responsabilidades e a difusão da ideia de autonomia administrativa e pedagógica das escolas, tendendo, no entanto, a induzir à padronização

${ }_{11}$ No neoliberalismo, tudo é medido segundo os lucros que produz (GERALDI, 2015, p. 383). 
curricular. Através da introdução da noção de responsabilização pelos resultados das avaliações, comumente atribuída à escola ou aos seus profissionais, difundem-se modalidades diferenciadas de relações contratuais entre Estado e funcionários, baseadas em desempenho. Por meio da avaliação em larga escala, disseminou-se uma lógica de gestão da educação pelo Estado, que vem se materializando por meio da ação do governo central, de governos subnacionais e hoje adentra as escolas.

A competição entre escolas e educadores também vem acontecendo por conta das demandas de cobrança interna trazidas por essas avaliações, organizando o planejamento pedagógico para esse fim, através de simulados e apostilamentos preparatórios.

Não queremos aqui condenar tais métodos avaliativos, compreendemos que possuem um propósito, conforme esclarece Luckesi (2011, p. 431):

A avaliação cumpre a função de subsidiar decisões sobre a prática pedagógica, ou seja, ela não tem como objetivo somente aparecer como uma pesquisa, e sua função não é apenas criar um ranking das instituições avaliadas. Seu objetivo fundamental é diagnosticar a qualidade da educação no país e orientar intervenções para a sua melhoria.

No entanto, o processo educativo não pode basear-se em tais avaliações, que, cada vez mais, acabam se tornando o objetivo final da aprendizagem. Gostaríamos também de destacar o fato de documentos, como a BNCC, estarem tão pautados nas avaliações em larga escala, conforme discute Gontijo (2015, p. 182):

Diferentemente das Diretrizes Curriculares Nacionais Gerais para a Educação Básica (BRASIL, 2013), o texto que trata dos princípios na BNCC revela uma forte preocupação com objetivos de aprendizagem a serem alcançados ao longo da educação básica. Nas páginas 8 e 9, são sinalizados percursos de aprendizagem, ou seja, objetivos a serem alcançados ao longo da vida escolar, demonstrando que, talvez, a BNCC vise somente a criar parâmetros para a avaliação em larga escala.

A preocupação da autora é também compartilhada por professores do país inteiro que estão submetidos a uma série de indicações externas, que cumprem objetivos bastante controversos quando considerada a função social da escola. Os conteúdos, após a BNCC, demonstram uma fragmentação ainda maior, e as escolas, também levadas a cumprir demandas imediatistas impostas por tais documentos, têm, por vezes, poucas condições objetivas para revisitar e rediscutir suas propostas de ensino, permanecendo preocupadas em ensinar conteúdos e preparar os alunos para as provas que estão por vir e buscando garantir índices satisfatórios para suas escolas e redes. 
É importante ressaltar que essas são demandas de um projeto político neoliberal, que espera esse comportamento meritocrático ${ }^{12}$ nas escolas, pois os resultados poderiam demonstrar aos empregadores onde se formavam os "melhores". As avaliações demonstrariam as "melhores" escolas e possíveis inadequações na aplicação do dinheiro público (GERALDI, 2015), e também serviriam de indicativo de onde se deveria aplicar mais recursos para melhorar a qualidade da escola. Foi por necessidade de parâmetros para elaborar as provas que surgiram os Parâmetros Curriculares Nacionais (BRASIL, 1997). E, posteriormente, dando sequência a eles, a BNCC.

\title{
5 CONSIDERAÇÕES FINAIS
}

Refletir sobre a BNCC é muito importante no cenário atual, tendo em vista que todas as formações de professores nas redes de todo o país estão pautadas em seu estudo e aplicabilidade em sala de aula. Nesse sentido, compreender a origem deste documento e o que está implicitamente ou explicitamente sugerido nele é essencial; essa, sim, deveria compor a formação dos profissionais da educação, para, depois, poderem explorar o documento na organização do planejamento.

Como qualquer outro documento norteador, a BNCC se coloca como um documento normativo necessário e de constituição coletiva e amplamente discutida, ao menos de acordo com os apontamentos dos documentos anteriores a ela. $\mathrm{O}$ que nos inquieta, contudo, é compreender qual a verdadeira intenção de um currículo nacional, pois se quer hegemonia ou treinamento, conforme discutimos anteriormente. Assim, concordamos com a reflexão de Gontijo (2015, p. 188):

\begin{abstract}
A definição de uma base comum nacional parece importante para que a escola cumpra seu objetivo de garantir oacesso ao conhecimento produzido ao longo da história humana. Entretanto, quando essa proposição se alinha, exclusivamente, à lógica da avaliação com a finalidade de produzir a melhoria de índices de desempenho nacionais pela via do rebaixamento do que é ensinado e, consequentemente, aprendido, podemos imaginar que ela poderá ser nociva ao desenvolvimento da educação.
\end{abstract}

Buscamos discutir também o conceito de competências, na intenção de compreender de onde se origina o termo presente no texto da BNCC e como essa palavra associada

\footnotetext{
${ }^{12}$ Segundo Freitas (2012), a meritocracia está na base da política liberal. Com base nessa política, cada sujeito é responsável pelo seu sucesso ou pelo seu fracasso, tudo depende do seu mérito. Neste caso, proporciona-se igualdade de oportunidade, mas não de resultados. "No caso da escola, diferenças sociais são transmutadas em diferenças de desempenho e o que passa a ser discutido é se a escola teve equidade ou não, se conseguiu ou não corrigir as 'distorções' de origem [...]” (FREITAS, 2012. p. 383).
} 
ao documento é capaz de direcionar todo um processo de organização escolar, influenciando na forma com que o docente trabalha.

A partir da compreensão do significado do vocábulo competência, presente tão fortemente na BNCC, podemos entender a relação entre escola e mercado de trabalho e a função estabelecida à educação a partir dessas ideias. Foi-nos possível estabelecer relações com a sociedade atual e o que se espera no campo da educação, observando tendências mercadológicas sendo incluídas nas escolas do país inteiro de forma bastante incisiva e obrigatória.

Portanto, esperamos que este artigo contribua para uma reflexão sobre o documento da base, pois o que buscamos foi aprofundar nosso conhecimento sobre a formulação do documento e seu embasamento teórico, a fim de que, a partir dessas informações, possamos compreender sua origem e finalidade no cenário educativo atual.

\section{REFERÊNCIAS}

BORGES, C. O debate internacional sobre competências: explorando novas possibilidades educativas. 2010. 139 f. Dissertação (Mestrado) - Faculdade de Educação, Universidade de São Paulo, São Paulo, 2010.

BRASIL. Constituição (1988). Constituição [da] República Federativa do Brasil. Brasília: Senado Federal, 1988. Disponível em: http://www.planalto.gov.br/ccivil_03/ constituicao/constituicao.htm. Acesso em: 11 jul. 2019.

BRASIL. Lei no 9.394, de 20 de dezembro de 1996. Estabelece as diretrizes e bases da educação nacional. Brasília: Diário Oficial da União, 23 de dezembro de 1996. Disponível em: http://www.planalto.gov.br/ccivil_03/leis/L9394.htm. Acesso em: 11 jul. 2019.

BRASIL. Parâmetros curriculares nacionais: língua portuguesa. Brasília: Secretaria de Educação Fundamental, 1997.

BRASIL. Diretrizes Curriculares Nacionais da Educação Básica. Brasília: MEC, SEB, DICEI, 2013.

BRASIL. Lei no 13.005 de 2014. Estabelece o Plano Nacional de Educação (PNE). Disponível em: http://pne.mec.gov.br/18-planos-subnacionais-de-educacao/543plano-nacional-de-educacao-lei-n-13-005-2014. Acesso em: 23 jul. 2019.

BRASIL. Base Nacional Comum Curricular: Educação Infantil e Ensino Fundamental. Brasília: MEC/Secretaria de Educação Básica, 2017. Disponível em: http:// basenacionalcomum.mec.gov.br/images/BNCC_EI_EF_110518_versaofinal_site.pdf. Acesso em: 01 jul. 2019.

BRASIL. Lei no 13.415 de 2017. Estabelece as diretrizes e bases da educação nacional. Disponível em: http://www.planalto.gov.br/ccivil_03/_Ato2015-2018/2017/Lei/ L13415.htm\#art4. Acesso em: 23 jul. 2019. 
FREITAS, L. C. Os reformadores empresariais da educação: da desmoralização do magistério à destruição do sistema público de educação. Educação e Sociedade, Campinas, v.33, n. 119, p. 379-404, abr./jun. 2012.

FREITAS, F. M.; SILVA, J. A.; LEITE, M. C. L. Diretrizes Invisíveis e Regras Distributivas nas Políticas Curriculares da Nova BNCC. Currículo sem Fronteiras, online, v. 18, n. 3, p. 857-870, set./dez. 2018. Disponível em: http://www.curriculosemfronteiras.org/ vol18iss3articles/freitas-silva-leite.pdf. Acesso em: 10 jul. 2019.

GERALDI, J. W. O ensino de língua portuguesa e a Base Nacional Comum Curricular. Revista Retratos da Escola, Brasília, v. 9, n. 17, p. 381-396, jul./dez. 2015. Disponível em: http://retratosdaescola.emnuvens.com.br/rde/article/view/587. Acesso em 10 jul. 2019.

GONTIJO, C. M. M. Base Nacional Comum Curricular (BNCC): Comentários Críticos. Revista Brasileira de Alfabetização - ABAlf, Vitória, v.1, n. 2, p. 174-190, jul./dez. 2015.

LUCKESI, C. C. Avaliação da aprendizagem: componente do ato pedagógico. 1. ed. São Paulo: Cortez, 2011.

MACEDO, E. Base Nacional Curricular Comum: a falsa oposição entre conhecimento para fazer algo e conhecimento em si. Educação em Revista, Belo Horizonte, v. 32, n. 02, p. 45-67, abr./jun. 2016.

MERCADANTE, A. Apresentação. In: BRASIL. Diretrizes Curriculares Nacionais Gerais da Educação Básica. Brasília: MEC, SEB, DICEI, 2013. p. 4.

MORIN, E. Os 7 saberes necessários à educação do futuro. São Paulo: Cortez, 2011.

PERRENOUD, P. Construir as Competências desde a Escola. Porto Alegre: Artmed Editora, 1999.

SAVIANI, D. Escola e democracia. São Paulo: Cortez; Campinas: Autores Associados, 1986.

SAVIANI, D. Pedagogia histórico-crítica: primeiras aproximações. 11. ed. Campinas, SP: Autores associados, 2013.

SAVIANI, D. Pedagogia histórico-crítica: primeiras aproximações. 10 ed. Campinas, SP: Autores Associados, 2008.

SILVA, R. S. Apresentação. In: BRASIL. Base Nacional Comum Curricular: Educação Infantil e Ensino Fundamental. Brasília: MEC/Secretaria de Educação Básica, 2017. p. 5. Disponível em: http://basenacionalcomum.mec.gov.br/images/BNCC_EI_ EF_110518_versaofinal_site.pdf. Acesso em: 01 jul. 2019.

SOUSA, S. A. Avaliação colaborativa e com controle social. Revista Retratos da Escola, Brasília, v. 7, n. 12, p. 65-75, jan./jun. 2013.

SOUZA, A. M. R.; GIORGI, M. C.; ALMEIDA, F. S. Uma análise discursiva da BNCC antes e depois do golpe de 2016. Cad. Letras UFF, Niterói, v. 29, n. 57, p. 97-116, 2º sem. 2018. 
TRICHES, E. F.; ARANDA, M. A. de M. A Formulação da Base Nacional Comum Curricular (BNCC) como ação da Política Educacional: breve levantamento bibliográfico (2014-2016). Realização, [S.1.], v. 3, n. 5, p. 81-98, jun. 2016. Disponível em: http://ojs. ufgd.edu.br/index.php/realizacao/article/view/6362. Acesso em: 23 jul. 2019.

(C) $(1) \Theta$

Data de submissão: 02/06/2020

Data de aceite: 06/06/2020 